\title{
Effect of Exports on the Economic Growth of Brazilian Microregions: An Analysis with Geographically Weighted Regression
}

\author{
Augusta Pelinski Raiher ${ }^{1}$, Alysson Luiz Stege ${ }^{1} \&$ Alex Sander Souza do Carmo ${ }^{1}$ \\ ${ }^{1}$ Universidade Estadual de Ponta Grossa (UEPG), Professors in the Economy Post-Graduation Program, \\ Department of Economy, State University of Ponta Grossa, Brazil \\ Correspondence: Augusta Pelinski Raiher, Universidade Estadual de Ponta Grossa (UEPG), Professors in the \\ Economy Post-Graduation Program, Department of Economy, State University of Ponta Grossa, Brazil. E-mail: \\ apelinski@gmail.com
}

Received: October 9, 2017

Accepted: October 29, 2017

Online Published: November 20, 2017

doi:10.5539/ijef.v9n12p236

URL: https://doi.org/10.5539/ijef.v9n12p236

\begin{abstract}
This study aimed at analyzing the effect of exports on the economic growth of Brazilian microregions in 2010, based on the theoretical model developed by Feder (1982). The hypothesis is that the economic growth of a region results from the existing productivity differential between the exporting and non-exporting sectors, as well as from the externality generated by the exporting sector in the economy. To reach the results, a geographically weighted regression was estimated, identifying a positive effect on the externality in practically all the Brazilian microregions. Regarding productivity, its effect was limited to the microregions close to the two largest ports in Brazil.
\end{abstract}

Keywords: exports, economic growth, microregions, geographically weighted regression

\section{Introduction}

The main aim of this research was to test the hypothesis of the growth model developed by Feder (1982) for Brazil, using data from different microregions. The central hypothesis of this model points out that the exports play a central role in the economic growth of the regions, due to the fact that this sector provokes indirect effects on the whole economy, as a result of the positive externalities generated between both sectors. Thus Feder's theoretical model (1982) allows the measurement of indirect effects from exports on the economic growth, which is the main virtue of this model.

It seems important to highlight that it is possible to find some studies that tested the central hypothesis of this model in the literature (Feder, 1982; Seijo, 2000; Ibrahim, 2002; Cantú \& Mollik, 2003; Mehdi \& Shahryar, 2012). However, most of these studies [except for Cantú and Mollik (2003)] used data from countries to test the model central hypothesis, while in this study, as mentioned before, the data base to be used was disaggregated for the Brazilian microregions. The use of microregional data aims at taking into consideration local heterogeneities and spatial dependence to capture the effect of exports on the economic growth.

The choice of Brazilian microregions as a geographical delimitation, instead of towns, originated from the argument put forward by Breitbach (2008). For this author, the use of microregions as the analysis space provides the researcher with a more suitable degree of approximation to the economic and social relationships that characterize the 'local environment', which is defined as a sufficiently small space, in which the proximity between the agents favors the creation of synergies able to keep a localized economic system working.

Another important aspect to be taken into consideration is that, as the variable under study is exports, many times the production might be carried out in peripheral towns, but the exporting company might be located in a town which is considered central to the region, and the value of exports might be ascribed to that town. For this reason, data regarding towns might overestimate or underestimate the real value exported by the town, impairing the analysis results. On the other hand, with a microregional sample, this effect tends to be mitigated.

Perobelli and Haddad (2006) pointed out that the use of local data allows the identification of two spatial effects: spatial dependence and spatial heterogeneity. The spatial dependence occurs due to the presence of spatial agglomerations, preventing geographical data from being independent one from another. While spatial heterogeneity occurs because each region has intrinsic characteristics which make them unique; for this reason, it 
is possible to identify different spatial patterns in the exports, as well as in the economic growth.

Therefore, the econometric technique to be used for the empirical model estimation has, necessarily, to take into consideration these two effects. For this reason, this study will estimate the empirical model parameters through the Geographically Weighted Regression technique (GWR); originally developed by Fotheringham, Brundson and Charlton (2002).

This technique enables the adjustment of a regression model that accounts for the heterogeneity of the data, weighting the estimates of parameters through the geographical location of the remaining observations of the data set. Thus instead of measuring the mean effect of exports on the growth, it is possible to estimate the effect for each microregion, so that it becomes possible to observe more clearly the microregions which are most affected by exports. After that, it will be possible to develop specific public policies targeting local interests.

In addition to this introduction, this paper is divided into four sections. Section 2 briefly describes the theoretical model by Feder (1982) and presents some empirical studies that evaluated the effect of exports on the economic growth in the light of this model. Section 3 addresses the methodology to be employed in this study, outlining both the empirical model and the parameter estimation strategy. In section 4 , an exploratory analysis of spatial data is carried out, and the results obtained from the empirical model estimation are discussed. Section five presents the final considerations.

\section{Literature Review}

As mentioned in the introduction above, the main objective of this research was to estimate the effect of exports on the economic growth of Brazilian microregions based on the model developed by Feder (1982). It seems relevant to emphasize that this model does not seek to quantify the direct effect of exports on the economic growth, but rather its indirect effects are addressed, which are two: the first results from the productivity differential existing between the exporting sector and the non-exporting sector. Feder (1982) pointed out that there are several factors that might result in higher productivity of the exporting sector, the higher competition of the international market outstands for leading firms to invest in more efficient production and management techniques, as well as in workforce qualification.

The second effect occurs through the positive externality that the exporting sector exercises on the non-exporting sector. However, Feder's model (1982) does not clarify what kind of externality is generated by the exporting sector over the economy non-exporting sector. At the same time, it is possible to infer the management techniques (organizational capital) or workforce qualification (human capital) used in exporting firms that might be followed by the domestic firms. Considering both effects previously presented, the main equation in the Feder's model (1982) takes the following form:

$$
\frac{\dot{\mathrm{Y}}}{\mathrm{Y}}=\alpha\left(\frac{\mathrm{I}}{\mathrm{Y}}\right)+\beta\left(\frac{\dot{\mathrm{L}}}{\mathrm{L}}\right)+\lambda\left(\frac{\dot{\mathrm{X}}}{\mathrm{X}}\right)\left(\frac{\mathrm{X}}{\mathrm{Y}}\right)+\varnothing\left(\frac{\dot{\mathrm{X}}}{\mathrm{X}}\right)\left(\frac{\mathrm{Y}-\mathrm{X}}{\mathrm{Y}}\right)
$$

Parameters $\alpha$ and $\beta$ will capture, respectively, the effect of the investment growth rate and the workforce on the product growth rate; while parameter $\lambda$ will identify the externality effect and the coefficient $\emptyset$ will measure the productivity differential effect. Feder (1982) defended that the intensity of the externality effect is a function of the relation between the non-exporting sector production and the exporting sector production, taking into consideration that the lower the participation of the exporting sector in the economy total is, the higher the effect of externalities is. More specifically, this equation will be used to specify the econometric model of this study (Note 1).

Using data from underdeveloped countries in the period between 1964 and 1973, Feder (1982) tested his theoretical model and the results evidenced that the productivity differential leads to economic growth, confirming the hypothesis that the exporting sector presents higher productivity than the non-exporting sector. In addition to this productivity differential, the results observed also revealed the existence of a positive externality of the exporting sector over the non-exporting one. The remaining variables inserted in the model, investment and workforce, presented positive and statistically significant coefficients, as expected.

Similar result was also found by Ibrahim (2002). In this study, data from six Asian countries: Hong Kong, South Korea, Malaysia, the Philippines, Singapore and Thailand were used. From the six countries under analysis, four presented productivity differentials between the exporting and non-exporting sectors and, in addition to that, except for the Philippines, in all the other countries there is a positive externality of the exporting sector over the economy. On the other hand, the author observes that this effect tends to be stronger in less developed countries than in the developed ones, since the differences between the exporting and non-exporting sectors, regarding productivity, are much more evident in less developed countries than in developed ones. 
Using a broader sample (a group of 72 developing countries), Seijo (2000) verified that the positive externalities generated by the exporting sector have positive effect on the economic growth of countries. Later on, in an attempt to test the robustness of the model, the author divided the sample into two groups of developing countries (medium and low), considering the income level. In both samples, the results confirmed the previous evidence, that exports generate positive externality over the non-exporting sector. Finally, in the last robustness analysis, the author divided the sample again, considering the geographical point of view, into three groups: Africa, South America and Asia. In this case, only for the African countries, the coefficient associated to externalities was positive and statistically significant, since for the other two groups (Latin America and Asia) the coefficient was positive, but not significant.

More recently, Mehdi and Shahryar (2012) estimated Feder's model (1982) for some sectors of the Iranian economy, considering the period between 1961 and 2006. The sectors considered in the study were: industry/mining, agriculture and services. Those authors' main objective was to estimate the effects of exports on the economic growth of these sectors. In all estimates, the authors verified that exports presented positive and significant effects on the economic growth of the three sectors under analysis.

A common point in the studies previously listed is that they used data bases from countries in their estimates. Cantú and Mollik (2003), however, developed some studies using data from 32 Mexican States in the period from 1993 to 1998. In all the models estimated, the capital did not present statistical significance, and the growth of the production factor 'work' presented negative signal, contrary to what had been expected. Moreover, although the effects of externality were positive and statistically significant, they were very small, close to zero. Thus, the results found in this study confirm only the assumptions of Feder's model (1982).

Regarding the Brazilian economy, Galimberti and Caldart (2010) estimated the Feder model, using spatial data from 22 municipalities belonging to Corede Serra, a region located in Rio Grande do Sul. The period of time considered by the authors was from 1997 to 2004. As a result, they identified a productivity differential between the export sector and the non-export sector, and this differential has a positive and statistically significant effect on the region's economic growth.

It seems important to emphasize that this study is aligned with the study by Cantú and Mollik (2003), since it also proposes to use data from regions instead of countries. However, this research advances in relation to the technique employed to estimate the empirical model. While Cantú and Mollik (2003) estimated the empirical model without taking into consideration the spatial component in the estimates (which makes the results obtained somehow biased due to the disregard of heterogeneity and spatial dependence), this study will take that into consideration by using the Geographically Weighted Regression (GWR).

This technique, originally developed by Fotheringham, Brunsdon and Charlton (2002), has been widely used to model processes which are not spatially uniform, that is, processes that vary from region to region regarding the mean and variance among other variables. Therefore, the main focus of the GWR technique is to adjust a regression model that takes this heterogeneity into consideration, adjusting a model for each region, weighting the estimates of the parameters through the geographical location of the remaining observations in the data set.

\section{Methodology}

This study uses two distinct methodologies, which are complementary, to analyze the local effect of exports on the economic growth of Brazilian microregions in the light of the theoretical model developed by Feder (1982), which are: Spatial Data Exploratory Analysis (SDEA) and Geographically Weighted Regression. In this section, the SDEA and the Geographically Weighted Regression are initially presented. Next, the empirical model and the data source are outlined.

\subsection{Spatial Data Exploratory Analysis (SDEA)}

The spatial data exploratory analysis (SDEA) is the collection of techniques that describes and visualizes the spatial distributions, identify atypical sites (spatial outliers) and finds out patterns of spatial associations (spatial clusters) and suggests different spatial regimes (Anselin, 1995). In this article, three SDEA common statistics are calculated, which are: The Global Univariate Moran I, the global bivariate Moran I and the LISA statistics.

The global univariate Moran I value measures the spatial correlation degree, that is, whether there is similarity of values of a particular variable with the similarity of location of the same variable. Mathematically, the statistics are provided through a matrix by:

$$
I=\frac{n}{S_{0}} \frac{z^{\prime} W z}{z^{\prime} z}
$$


where $n$ is the number of microregions; $z$ are the values of the standardized relevant variable; $W z$ are the mean values of the standardized relevant variable in the neighbors, following a particular weighting matrix $W ; S_{0}$ is the matrix of the elements of the weighting matrix $W$.

The Moran I value ranges between -1 and 1 . A positive Moran I value indicates positive spatial autocorrelation, that is, high (or low) values of a relevant variable tend to be surrounded by high (or low) values of this variable in the neighboring regions. While a negative Moran I value indicates a negative spatial autocorrelation, where, a high (or low) value of the relevant variable in a region tends to be surrounded by low (or high) values of the same variable in the neighboring regions.

The spatial correlation degree can be measured in a bivariate context, by calculating the statistics of the global bivariate Moran I. In such case, there is an attempt to find out whether the value of a variable under observation in a certain region keeps any association with the values of another variable observed in neighboring areas. In formal terms, the global statistics for two different variables in their matrix format is given by Equation 3 :

$$
\mathrm{I}=\frac{\mathrm{n}}{\mathrm{S}_{0}} \frac{\mathrm{z}_{1}{ }^{\prime} \mathrm{W} \mathrm{z}_{2}}{\mathrm{z}_{1} \mathrm{z}_{2}}
$$

Where $n$ is the number of regions; $z_{1}$ and $z_{2}$ are the standardized relevant variables; $W z_{2}$ is the mean value of the standardized variable $z_{2}$ in the neighbors following certain weighting matrix $W ; S_{0}$ is the sum of the elements of the weighting matrix $W$.

The value of Equation (03) can be positive or negative. Its interpretation for a positive value is the following: the regions that present high (low) value for certain variable, in general, tend to be surrounded by towns with high (low) value for another variable. However, if this value is negative, it means that: the regions that present high (low) value for certain variable tend to be surrounded by towns with low (high) value for another variable.

LISA statistics, in turn, also known as local Moran I, measures the individual contribution of each observation in the global Moran I statistics, capturing simultaneously the spatial associations and heterogeneities (Miller, 2004). Mathematically, the statistics for the observation at $i$-th are given by Equation 4:

$$
\mathrm{I}_{\mathrm{i}}=\mathrm{z}_{\mathrm{i}} \sum_{\mathrm{j}=}^{\mathrm{j}} \mathrm{w}_{\mathrm{ij}} \mathrm{z}_{\mathrm{j}}
$$

where $z_{i}$ is the value of the standardized relevant variable of the $i$-th; $z_{j}$ is the value of the standardized relevant variable of the $j$-th observation; and, $w_{i j}$ are the mean values of the standardized relevant variable in the neighbors, according to certain weighting matrix W. According to Anselin (1995), the sum of the LISA statistics is proportional do the global Moran I statistics, and might be interpreted as an indicator of a local spatial cluster.

For each observation (in this article for each microregion) a $I_{i}$, is calculated obtaining $n$ values of $I_{i}$, whose most efficient form of presenting is through the LISA (Note 2) significance map. The LISA cluster map shows the regions with significant statistics in the local Moran I.

\subsection{Geographically Weighted Regression}

When working on socioeconomic phenomena one can assume that they might vary between the regions under analysis, that is, the phenomena are not constant between regions. Fotheringham, Brunsdon and Charlton (2002) propose an econometric method, called Geographically Weighted Regression (GWR), which allows the study of phenomena which are not constant between regions.

According to Fotheringham, Brundson and Charlton (2002), each region might have different relations, resulting in varied coefficients, for this reason GWR appears as an alternative to the classical linear regression model, enabling the existence of one coefficient for each region, indicating the non-stationarity of the responses given by the explaining variables.

GWR is specified as:

$$
\mathrm{y}_{\mathrm{i}}=\beta_{\mathrm{o}}\left(\mathrm{u}_{\mathrm{i}}, \mathrm{v}_{\mathrm{j}}\right)+\sum_{\mathrm{k}} \beta_{\mathrm{k}}\left(\mathrm{u}_{\mathrm{i}}, \mathrm{v}_{\mathrm{j}}\right) \mathrm{x}_{\mathrm{ik}}+\epsilon_{\mathrm{i}}
$$

where: $y_{i}$ is the dependent variable for the $i$-th region; $\left(u_{i}, v_{j}\right)$ are the geographical coordinates of the $i$-th region in the space (for example, latitude and longitude); $\beta_{k}\left(u_{i}, v_{j}\right)$ is the local coefficient of the $i$-th region, which is a function of the geographical position $\left(u_{i}, v_{j}\right) ; x_{i k}$ are the explaining variables of each region $i$, when $k$ is the number of independent variables for each region; and, $\epsilon_{i}$ is the random error term for the $i$-th region which follows a normal distribution with mean equal zero and constant variance.

Also, according to Fotheringham, Brundson and Charlton (2002), the GWR model estimates one equation for each region, using data subsamples. The regions that take part in these subsamples are chosen according to their distance in relation to the place for which the regression is being calculated, where closer regions have greater 
influence than the farther ones.

The GWR estimation is based on the weighted least squares method, and is calculated as follows:

$$
\hat{\beta}\left(u_{i}, v_{j}\right)=\left(X^{\prime} W\left(u_{i}, v_{j}\right) X\right)^{-1}\left(X^{\prime} W\left(u_{i}, v_{j}\right) Y\right)
$$

where: $\hat{\beta}$ é is a vector with the $\beta$ estimates; $\mathrm{X}$ is a vector of the independente variables; $\mathrm{Y}$ is a vector of the dependent variable: and, $W\left(u_{i}, v_{j}\right)$ is a diagonal weighting matrix with dimension $n \times n$.

The elements of the matrix main diagonal $W\left(u_{i}, v_{j}\right)$, named $w_{i j}$, are the weights used to estimate the equation coefficients. These weights are based on the distance of the $i$-th region from the other regions in the subsample, selected through the kernel spatial function (Note 3). The kernel spatial function might be fixed or adaptive (Note 4), depending on the bandwidth (Note 5). This study employs the adaptive kernel, since the bandwidth used in this type of spatial kernel adapts to the number of observations around the point to be observed, obtaining more efficient and less biased estimates.

Bandwidth is one of the important points in GWR, since according to Fotheringham, Brundson and Charlton (2002), GWR results are sensitive to this parameter choice. Therefore, a method should be adopted that determines in a non-arbitrary way the optimal bandwidth. The Akaike information criterion was used to determine the optimal bandwidth in this study.

Thus GWR is presented as an alternative to control both the spatial heterogeneity and the spatial dependence, since this technique allows the inclusion of spatial dependence in the spatial lag form (SAR model) and is specified by Equation 7:

$$
\mathrm{y}_{\mathrm{i}}=\beta_{\mathrm{o}}\left(\mathrm{u}_{\mathrm{i}}, \mathrm{v}_{\mathrm{j}}\right)+\rho\left(\mathrm{u}_{\mathrm{i}}, \mathrm{v}_{\mathrm{j}}\right) \mathrm{Wy}_{\mathrm{i}}+\sum_{\mathrm{k}} \beta_{\mathrm{k}}\left(\mathrm{u}_{\mathrm{i}}, \mathrm{v}_{\mathrm{j}}\right) \mathrm{x}_{\mathrm{ik}}+\epsilon_{\mathrm{i}}
$$

where: $W y_{i}$ is the spatially lagged dependent variable through a matrix of spatial weights and $\rho$ is the spatial autoregressive coefficient. This model is estimated by the method of instrumental variables due to the endogeneity of the variable $W y_{i}$, which has as instruments the spatially lagged explaining variables $W x$. GWR also allows for the Spatial Error Model (SEM), the Spatial Durbin Model (SDM) and the Crossed Spatial Regressive Model (SLX) (Note 6).

\subsection{Empirical Strategy and Data Source}

To construct Feder's empirical model (1982), the following GWR model will be estimated considering the spatial effects (Note 7):

$$
\begin{gathered}
\operatorname{TPIB}_{i}=\beta_{o}\left(u_{i}, v_{j}\right)+\rho\left(u_{i}, v_{j}\right) W T P I B_{i}+\beta_{1}\left(u_{i}, v_{j}\right) I N C F_{i}+\beta_{2}\left(u_{i}, v_{j}\right) F T R A B_{i}+\beta_{3}\left(u_{i}, v_{j}\right)\left(\operatorname{CRESX}_{i} *\right. \\
\text { PARTX } \\
\text { PAR } \left._{i}\right)+\beta_{4}\left(u_{i}, v_{j}\right)\left[\operatorname{CRESX}_{i} *\left(1-\operatorname{PARTX} X_{i}\right)\right]+\epsilon_{i}
\end{gathered}
$$

where: $T P I B_{i}$ represents the Gross Domestic Product (GDP) growth rate in the $i$-th microregion; WTPIB $i$

is the Gross Domestic Product (GDP) growth rate in the $i$-th microregion between 2009 and 2010, spatially lagged using the spatial weight matrix of the type queen; $I N C F_{i}$ is the investment in physical capital in relation to the GDP of the $i$-th microregion; FTRAB $B_{i}$ is the population growth rate in the $i$-th microregion; CRESX $X_{i}$ is the exports growth rate in the $i$-th microregion; PARTX $_{i}$ corresponds to the participation of exports in the GDP in the $i$-th microregion. It seems relevant to emphasize that the term "CRESX $X_{i} *\left(1-\right.$ PARTX $\left._{i}\right)$ " measures the exports externality and the "CRESX $X_{i} * P_{A R T X_{i}}$ " measures the exports sector productivity differential in relation to that of the domestic market. The variable $T P I B_{i}$ is calculated based on the percentage variation of the GDP in 2010 in relation to the GDP in 2009; the GDP data of the microregions was collected from the site IPEADATA for 2009 and 2010 ( $\mathrm{R} \$$, prices from 2000). The value of industries in 2010 was used as proxy for the variable fixed capital investment $\left(I N C F_{i}\right)$ (Note 8). The variable $F T R A B_{i}$ was obtained at the site IPEADATA for 2010. The variable $\operatorname{CRESX}_{i}$ was measured based on the exports percentage variation in 2010 in relation to the 2009 exports; and the exports data was obtained at the site Aliceweb originally for the towns, but for the purposes of this study they were aggregated contemplating the microregions. The variable PARTX $X_{i}$, which is the participation of exports in the GDP of the $i$-th microregion, was obtained through the division of exports by the 2010 GDP. Details about the variables and how they were measured can be found in Appendix B.

\section{Analysis of Results}

In the 2000s, Brazil presented an important economic growth process, which was stopped in 2008 by the international financial crisis (Figure 1). In fact, between 2000 and 2008 the mean of the country economic growth was $8.3 \%$ year, while from 2008 and 2010 the growth was only $2.3 \%$. The favourable result in the first years of the period resulted mainly from the "commodities cycle" experienced by Brazil, which contributed to the economy 
dynamics and also to the formation of a surplus in current transactions. It seems relevant to emphasize that the expansion of international reserves allowed the reduction of constraints imposed by the balance of payments to the Brazilian economic growth with the 2008 crisis. Thus the existence of international reserves and the international flow of goods which was kept throughout the crisis (supported by the Chinese demand that had a smaller decrease), enabled the strategy of activation of the domestic economic activity through domestic policies of income and credit. In such context, even if the country presented lower growth rate between 2008 and 2010, it managed to impact positively the economy.

Brazilian exports showed an increase in terms of diversification, from 1183 products exported in 2010 to 1188 in 2014 (SH 4 digits). And within this export agenda, primary products resulted in an important percentage, with their main representatives: ore (13\% of exports in 2014); grains, seeds and cereals (12\%); meat (7\%); sugars (4\%); coffee and tea (3\%). With regard to trade partners, the country had a small increase between 2010 and 2014, from 226 importing countries to 228 , with China and the United States as its main partners, representing respectively $18 \%$ and $12 \%$ of the total value exported by the country. These characteristics - diversification of products and commercial partners - are important elements when seeking to reduce Brazil vulnerability to the oscillations of the international market (Note 9).

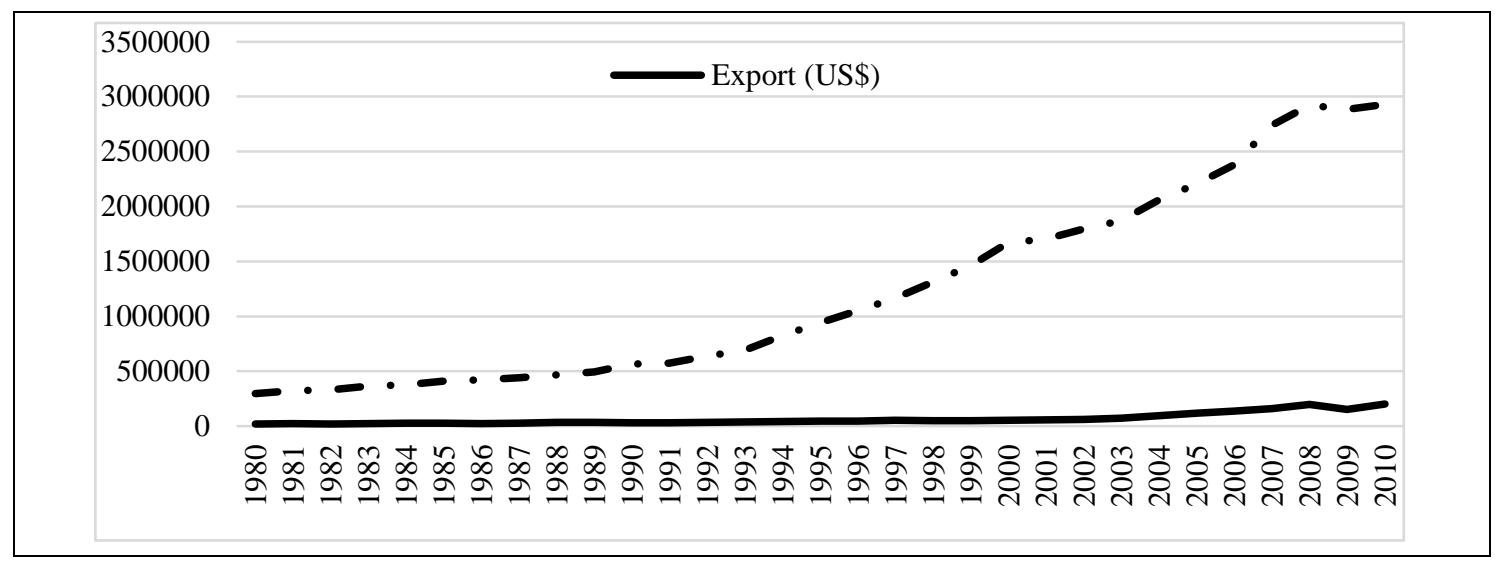

Figure 1. Gross Domestic Product (GDP) and Brazilian exports (US\$)- 1980 to 2010

Source: Elaborated by the authors with data from Ipeadata.

When comparing the exports evolution (Figure 1) a similar trend is seen, with a boom of external insertion in the 2000s, interrupted from 2008 on. Also, Figure 2 shows certain correlation (Note 10) between the exports growth rate and the Gross domestic product (GDP), in which in general, in periods of increase in exports tended to show increase in the product (and vice-versa). When the economic activity decreased, mainly in 20082009, the exports presented a sharp reduction, which was greater in the period under analysis.

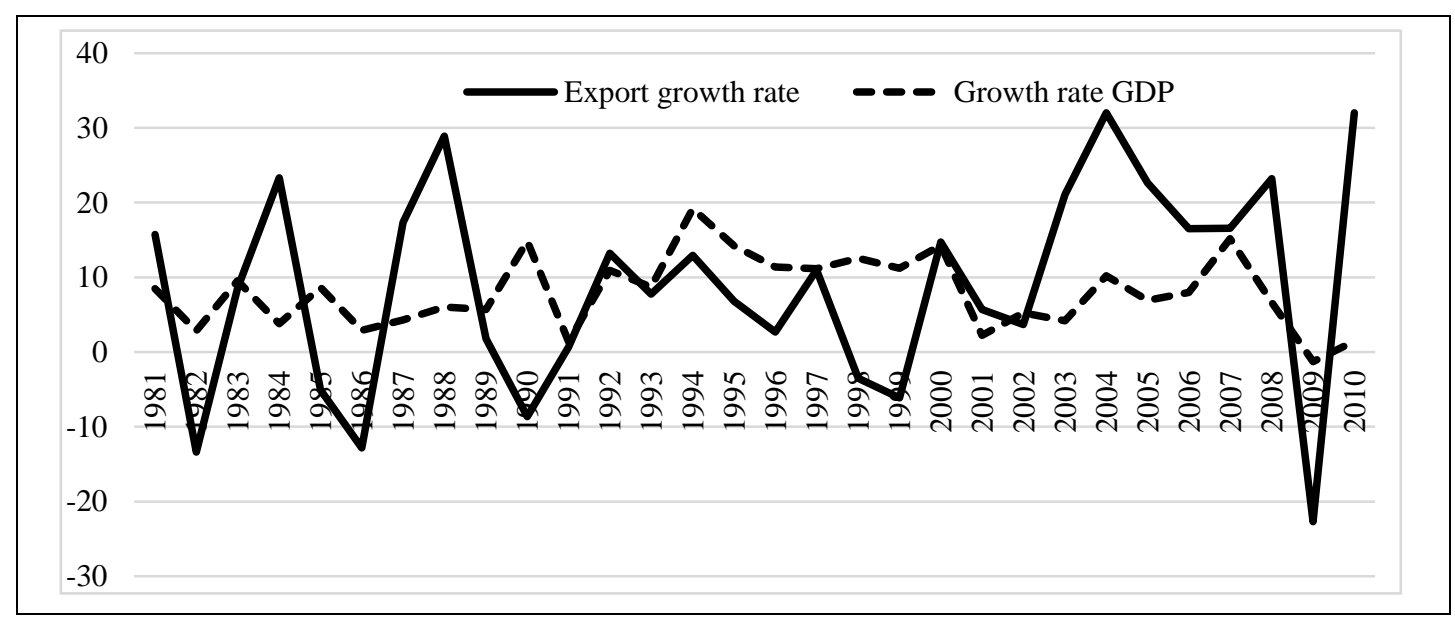

Figure 2. GDP and exports growth rate (\%) - 1981 to 2010

Source: Elaborated by the authors with data from Ipeadata. 
Since exports are part of the aggregated demand, it is natural to find a positive association between them. However, theoretically, as mentioned in the Feder's model (1982) exports might generate an effect in the economy which transcends their direct impacts, generating externality and also productivity differentials. These particularities might interfere directly in the economic dynamism of the country.

Figure 3 shows the process of international insertion of the Brazilian economy in a microregional perspective. In this Figure, an evolving process in the number of microregions is observed, considering that the percentage increased from 75\% (1997) to 83\% (2010) (Figure 3). That is, this result evidences that the Brazilian microregions were increasing their competitiveness, since they were managing to insert their products in the competitive international market.

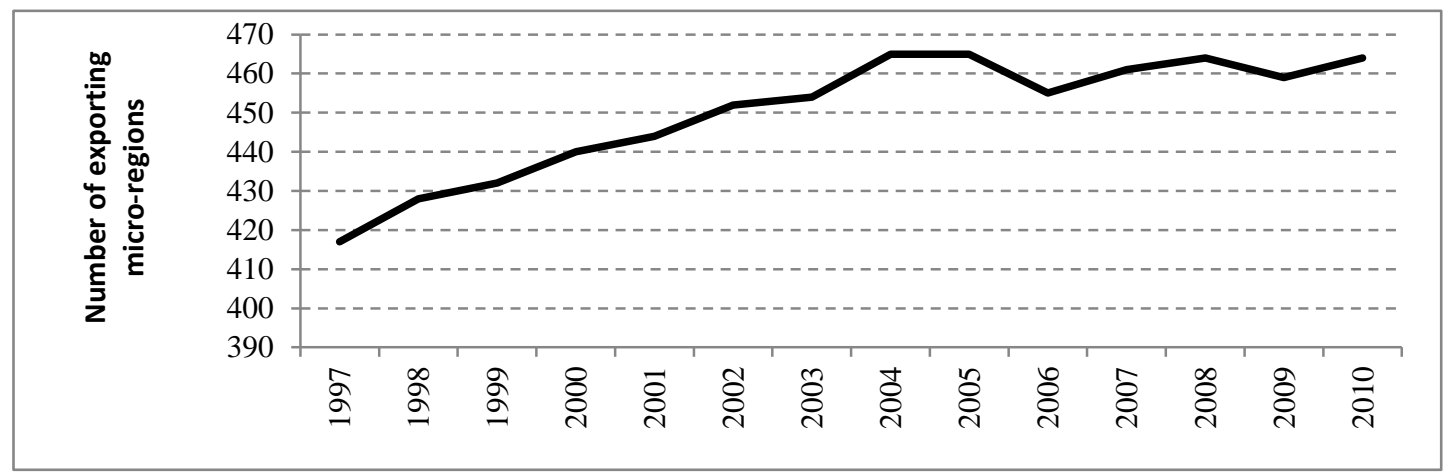

Figure 3. Number of Brazilian exporting microregions - 1997 to 2014

Source: Elaborated by the authors with data from Aliceweb.

However, the great problem regarding international insertion of the Brazilian microregions is that the magnitude of exports is not homogeneous, on the contrary, it is highly concentrated in some regions of the country. As shown in Figure 4(b) most exports (2010) were concentrated in some microregions, mainly the Southeast and South of the country, with a huge gap in regions North and Northeast.

Some authors point out structural issues in the productive sector, the availability of natural resources, government incentive, transport infrastructure, and the easy access to the external market, as elements that potentially explain this spatial heterogeneity of exports over the Brazilian territory (Perobelli \& Haddad, 2002; Betarelli Junior \& Almeida, 2009).

As regards economic development, heterogeneity is also seen in its distribution (Figure $4 \mathrm{a}$ ), so that only $43 \%$ of the microregions obtained a GDP growth above that of the Brazilian mean.

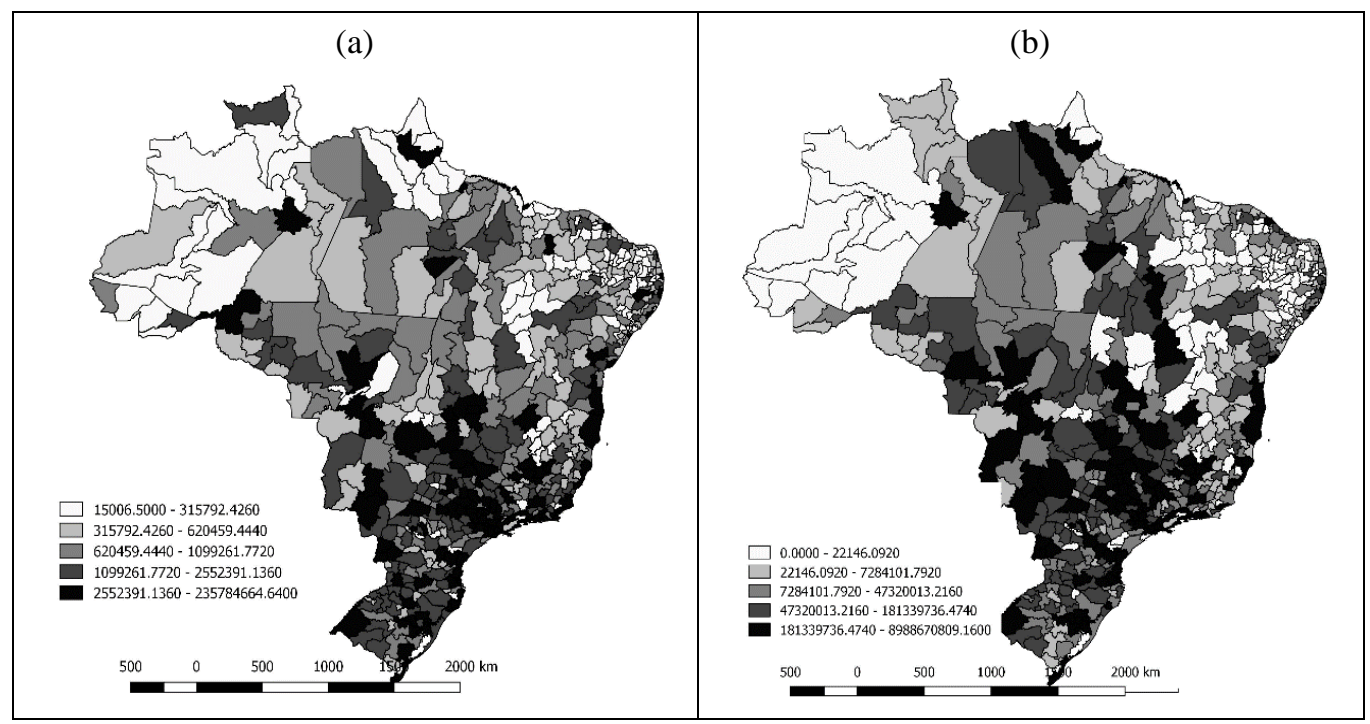

Figure 4. GDP (a) and exports (b) growth rate - Brazilian microregions -2010

Source: Elaborated by the authors with data from Ipeadata and AliceWeb. 
An interesting point that has been already highlighted in relation to the figures previously described, is the geographical proximity of microregions that present high GDP and exports values, suggesting the existence of a spatial autocorrelation in the data under investigation, which is confirmed in Table 1.

Table 1. Moran I coefficient (univariate and bivariate) - Brazilian microregions - 2010

\begin{tabular}{|c|c|c|c|c|}
\hline \multirow{2}{*}{ Moran I } & \multirow{2}{*}{ Variable analyzed } & \multicolumn{3}{|c|}{ Convention } \\
\hline & & Queen & Tower & 5 neighbors \\
\hline \multirow[t]{2}{*}{ Univariate } & GDP growth rate & $0,21^{*}$ & $0,21 *$ & $0,22^{*}$ \\
\hline & Exports & $0,17^{*}$ & $0,17 *$ & $0,18^{*}$ \\
\hline Bivariate & GDP versus exports growth rate & $0,10^{*}$ & $0,10^{*}$ & $0,10^{*}$ \\
\hline
\end{tabular}

Source: Calculated by the authors aided by the software GeoDa, based on the research data.

Note. An empirical pseudo-significance based on 999.999 random permutations; (*) significant at $1 \%$.

Table 1 presents the univariate global Moran I statistics, which presented a statistically significant positive coefficient for both the exports and the economic growth. This means that the regions that held high (low) amounts of exports were surrounded by microregions that also had high (low) exports values. Likewise, microregions with intense (reduced) economic growth were surrounded by microregions that also presented intense (reduced) economic growth. Therefore, not only were the values of exports/GDP growth concentrated in some spaces in 2010, but also these places were close one to another.

Table 1 also shows the bivariate global Moran I statistics analyzing the relation between economic growth and exports. Once more, a positive and significant coefficient was obtained, which means that the economic growth of microregions is related to the behaviour of the exports in the microregions around it. In this sense, the hypothesis that greater economic dynamism tends to concentrate in those microregions where the international insertion is higher is confirmed, optimizing the spillover effect of the results in the area surrounding these regions.

Taking that into consideration, the influence of exports in this process of economic growth is analyzed, seeking to capture its indirect effects: externality and productivity differential, as the central hypotheses of the theoretical model proposed by Feder (1982). Due to the existing heterogeneity in the economic growth distribution, a phenomenon that is confirmed by the local Moran I analysis (Figure 5), we opted for the analysis via estimation of the Geographically Weighted Regression (GWR), aiming at controlling both the spatial heterogeneity and the spatial dependence. In fact, Figure 5 confirms the spatial disparity in relation to both economic growth and exports. Regarding the latter, low-low clusters are seen mainly in the North and Northeast of the country, regions that present lack of infrastructure and competitive productive clusters, slowing international insertion. As regards the GDP growth, the dynamics of cluster formation is slightly different, since some heterogeneity is seen over the country, but one that does not follow a pattern of regional location neither of high-high clusters nor the low-low ones. Therefore, due to the existence of this uneven distribution, the Feder's model was estimated for the Brazilian microregions using the Geographically weighted regression.

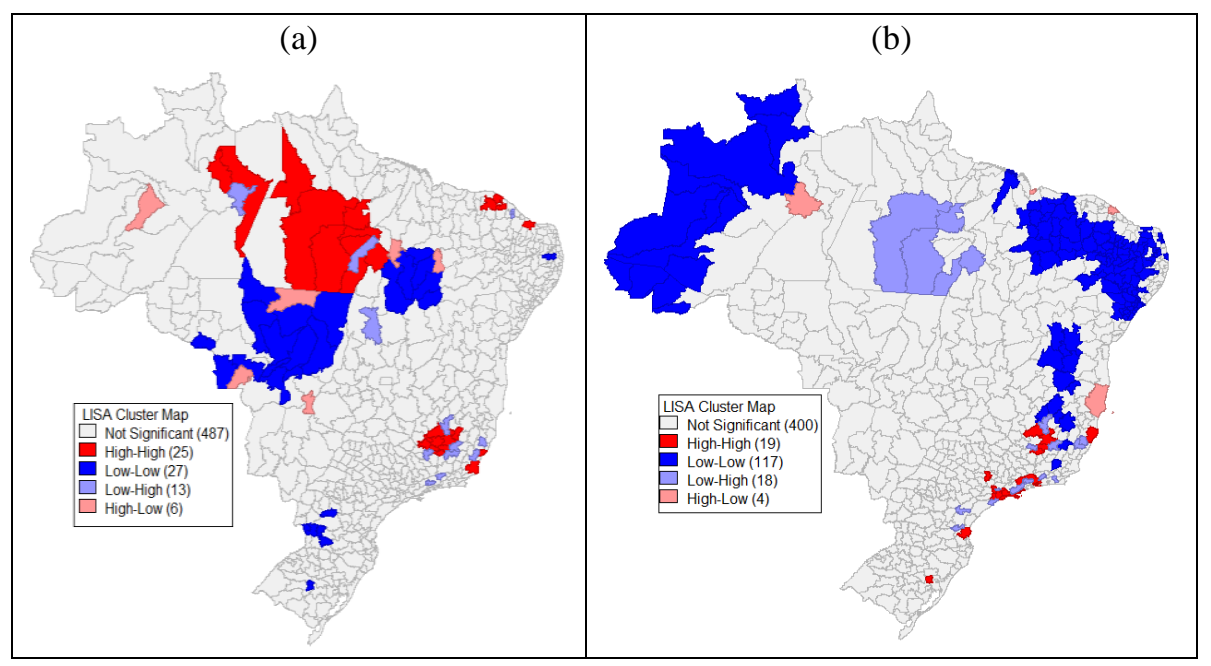

Figure 5. GDP growth (a) and exports (b) LISA map - Brazilian microregions -2010

Source: Estimated by the authors aided by the software GeoDa, based on the research data.

Note. The empirical pseudo-significance based on 999.999 random permutations. 
The results of the empirical model estimation described in Equation 08 are reported in Table 2 (Note 11). Based on the global model, a positive and statistically significant effect of the exports externality on the economic growth was observed. This basically results from the income and chain effects that exports possibly generate in each microregion economy. Regarding the income effect, by being inserted in the international market some region might create internal jobs which can boost the local commerce and other domestic industries. Moreover, a multiplying effect might be generated in the economy resulting from the existing linkage between the exporting sector and other domestic productive segments, also leading to competitiveness between these segments.

Therefore, the correlation observed between the economic growth of the Brazilian microregions and the insertion in the international market (Figure 4) is validated by the econometric results. Especially in relation to primary products, Brazil has a comparative advantage, a result of existing natural resources, as well as investments in research in this area that have been made over the years. These and other factors have raised the country competitiveness and placed it among the main exporters of these products, so that in 2010 Brazil ranked sixth in the ranking of the world agricultural exporters. All this efficiency somehow runs in the productive chain in which agriculture is inserted, generating externalities for the links that are especially interconnected in this sector. This requires more efficient inputs, specialized services, etc., which are available to the exporting sector as well as to domestic market production. Moreover, export industries linked to the primary sector (low-tech industry) also gain in competitiveness. Also, by analyzing the Brazilian export agenda, the low technology industry and the non-industrial products were seen to correspond to $42 \%$ of the Brazilian exports.

In addition to this, the injection of income that the exports promote, generates demand for domestically produced goods, fostering income and employment throughout the country. These arguments explain the positive and statistically significant coefficient for export externalities.

Table 2. Global results of the GDP estimates - Feder's model - Brazilian microregions - 2010

\begin{tabular}{ccc}
\hline Variable & Coefficient & Standard deviation \\
\hline CRESX $_{\mathrm{i}}\left(1-\right.$ PARTX $\left._{\mathrm{i}}\right)$ & $0,0357^{*}$ & 0,0035 \\
CRESX $_{\mathrm{i}} *$ PARTX $_{\mathrm{i}}$ & 0,0002 & 0,0004 \\
FTRAB $_{\mathrm{i}}$ & 0,4243 & 0,6452 \\
INCF $_{\mathrm{i}}$ & $0,2239^{*}$ & 0,2843 \\
$\rho$ & $0,55^{*}$ & 0,0661 \\
\hline
\end{tabular}

Source: Estimated by the authors aided by the software GWR, based on the research data.

Note. * significant at the $5 \%$ significance level. The term "CRESX $\left(1-\right.$ PARTX $\left._{i}\right)$ " is the proxy for the exports externality, and "CRESX ${ }_{i}$ * $P A R T X_{i}$ " refer to the variable "productivity differential" of the exporting sector in relation to that of the domestic market.

As regards the productivity differential of the exporting sector, its coefficient presented the signal expected, however, it was not statistically significant. This results might be due to the time interval under analysis, a period in which the international market was weak and part of the production that would have been sent to the external sector was displaced to supply the domestic market, resulting in similar productivity between the international and domestic markets.

It seems relevant to emphasize that from 2008 on the Brazilian government effected a series of anti-cyclic measures, such as the increase in credit through the public banks, the reduction of the interest basic rate, the housing program "Minha Casa, Minha Vida" (My house, my life) and the Federal fiscal waive regarding the payment of Industrialized Products Tax (Almeida, 2010). Mainly the latter, aimed at stimulating the domestic consumption of such products, balancing the production of industries that produced goods which benefited from the tax reduction, as well as the sectors backwards and forwards each productive chain. Therefore, these and other actions led the productive activity even during the international crisis, focusing on the domestic market and that, possibly, justifies the absence of the exporting sector productivity differential effect on the economic growth.

As for the remaining variables included in the model, both the physical capital and the economic growth spatial gap presented positive and/ statistically significant effect. Mainly, the parameter $\rho$ highlights a positive spillover of the GDP growth in the economic dynamics of the neighboring microregions. This shows that, when certain region grows, part of this growth also benefits the neighboring microregions, creating a virtuous cycle of growth.

All the previous analysis involved estimated global coefficients (Table 2 analysis). In certain situations, it is theoretically expected that some coefficient might be global, while other coefficients are supposedly global. The great advantage of the GWR is to provide local coefficients, that is, this technique recognizes that the effect of a 
variable is not exactly the same in all regions, on the contrary, it tends to vary from region to region.

To verify the hypothesis of stationarity of relationships represented by the variables considered in the empirical model, the test Monte Carlo was adopted (Appendix A, Table A1). Through this test, the null hypothesis of stationarity for the exports externality and productivity differential coefficients was rejected at a $5 \%$ significance level, that is, statistical evidence pointed out that the effects of these two variables are local.

Figure 6 shows the distribution of such coefficients, evidencing that, although the mean effect of the productivity differential was not statistically significant, in $20 \%$ of the microregions this impact exists [Figure 6(a)]. When observing the location of these microregions, they are seen to be located mainly in the regions Southeast and South of Brazil, which concentrated most of the country exports (Carmo, Raiher, \& Stege, 2016). As previously stated, these regions have higher availability of natural resources, better universities and transportation infrastructure, as well as easy access to the external market, due to the proximity to the main ports in the country (Santos, Rio de Janeiro, Paranaguá, Vitória and Itajaí). These elements might be interpreted as competitive advantages of these microregions to attract exporting companies, which, in turn, present higher productivity levels.

As regards exports externalities [Figure 6(b)], 96\% of the Brazilian microregions presented a positive and statistically significant coefficient. That is, basically along the whole Brazilian territory, the insertion in the international market presents an effect that goes beyond the injection of resources in the economy, generating indirect impacts that lead to a process of economic growth. These dynamics were not verified in 24 microregions, highlighting that these regions presented an important economic growth in the year under analysis, however, they did not present an exports value that matched this growth process [comparison between Figures 4(a) and 4(b)].

These results are important for the process of planning the economic development of the Brazilian microregions, demonstrating a significant potential of external insertion to have economic dynamism throughout the country, not only having a direct effect (GDP composition) but also indirect impacts on the economy.

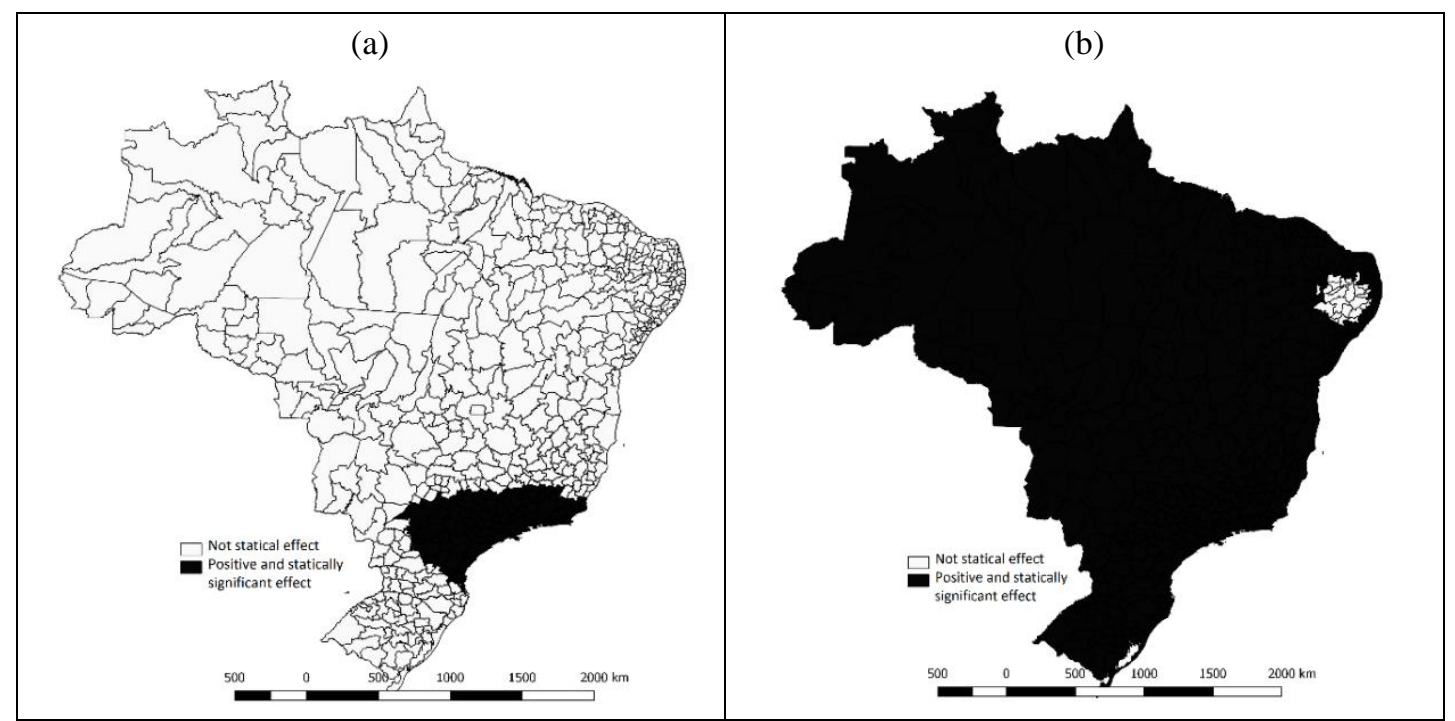

Figure 6. Spatial distribution of the productivity (a) and exports externality (b) statistically significant local coefficients - Brazilian microregions - 2010

Source: Elaborated by the authors from the results of the software GWR.

The same distribution of the local coefficients in Figure 6 is seen in Figure 7, however, in the latter the magnitude of the coefficients was evidenced (both the productivity differential and the externality) in each Brazilian microregion. In this case, the microregions in which the exports level was more intense (South, part of Southeast and Center-West) were seen to the present lower externalities; at the same time, in the microregions where the external insertion was lower, the externality impact was higher. That is, the internationalization of Brazilian products, might be an important way to the economic growth, mainly in those areas of the country that present greater weakness in terms of external insertion (North and Northeast), regions that also present lower economic dynamics. Regarding the productivity differential coefficient, the effect was seen to be higher in those microregions located closer to the coast, neighboring the main ports of the country.

Finally, the proximity between microregions that present higher relation between exports externality and the GDP 
growth and between the productivity differential and the economic dynamics was noticeable. This spatial pattern was confirmed by the Moran I statistics, which obtained a 0.94 coefficient for productivity and 0.91 for externality. Thus microregions with high (low) beta for productivity were surrounded by neighbors that also held high (low) beta for productivity. The same phenomenon was verified for the externality. Therefore, knowing this spatial dependence, public policies that aim at the external insertion might be applied to each space, obtaining very similar results in terms of economy dynamics.

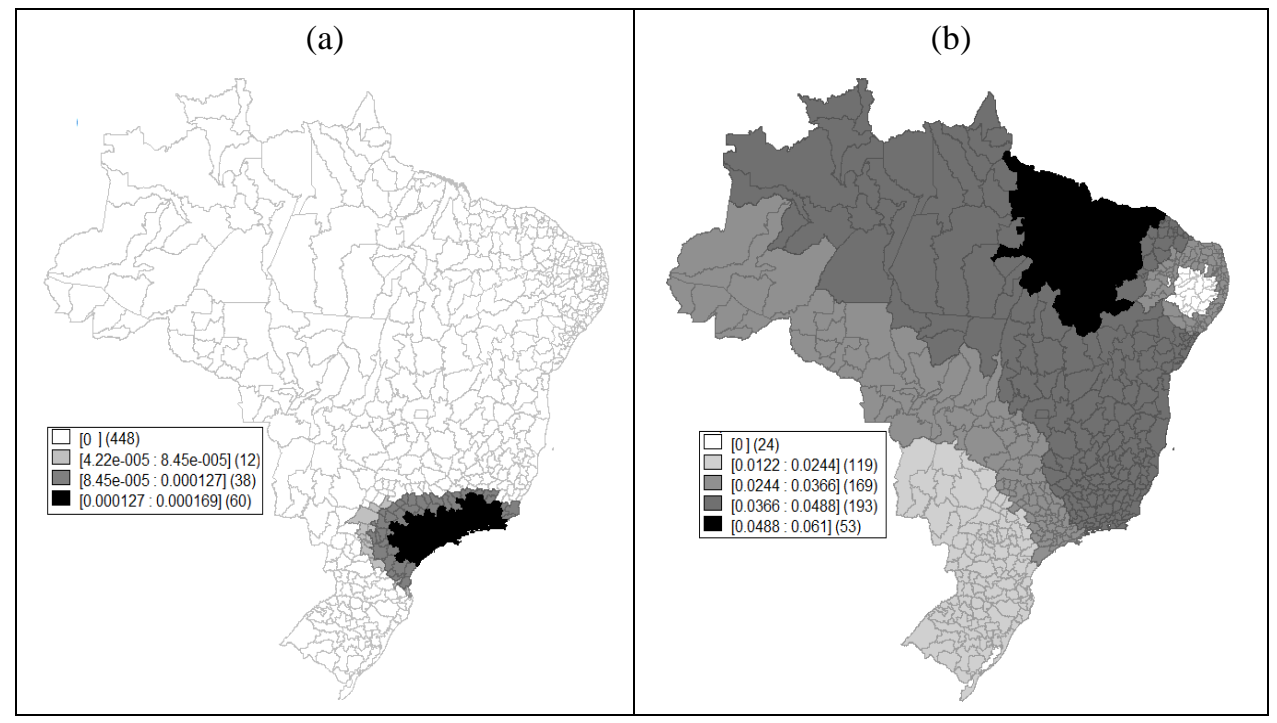

Figure 7. Spatial distribution of productivity (a) and exports externalities (b) effects (betas) - Brazilian microregions- 2010

Source: Elaborated by the authors from the results of the software GWR.

\section{Final Considerations}

This study aimed at verifying the local effect of exports in the economic growth of Brazilian regions in 2010 in the light of the Feder's theoretical model (1982). Basically, the theoretical hypothesis is that the economic growth of a region results from the existing productivity differential between the exporting and non-exporting sectors, as well as the externality generated by the economy exporting sector.

In methodological terms, a geographically weighted regression was estimated, and the hypotheses of the theoretical model were partially confirmed. As regards externality, its importance is visible to favour the GDP of almost all microregions of the country, mainly those whose international insertion is weak. That is, not only has a direct impact on the formation of the country GDP with the insertion of products in the international market, but also an indirect effect, generating spillovers, income effect, etc., throughout the productive chain of the sector. All these impacts are important for the economic dynamism, especially of the less developed regions of the country. Regarding productivity, its effect was limited to the areas close to the largest ports in the country.

From these results it is possible to direct specific policies to boost the international insertion of each microregion, seeking to homogenize the country competitiveness and, consequently, favoring a more intense economic growth, mainly in those areas which are economically weaker (North and Northeast). But, to achieve that it is necessary to rethink the exports flow, mainly in the North and Northeast, with the implementation of efficient ports in those regions.

Finally, specific policies are needed, aiming at the microregions insertion in the international market, mainly North and Northeast, and also the deepening of the commercial relations already existing in the country. The results found in this study point out to the fact that if the country manages to insert more microregions in the international market, the economic growth might be even greater and more homogeneous all over the country.

\section{References}

Almeida, E. S. (2012). Econometria espacial aplicada. Campinas, SP: Alínea.

Almeida, J. G. (2010). Como o Brasil superou a Crise. In Dossiê da crise II. AKB. Retrieved from http://www.ppge.ufrgs.br/akb/dossie-crise-II.pdf 
Anselin, L. (1995). Local indicators of spatial association - LISA. Geographical Analysis, 27(2), 93-115. https://doi.org/10.1111/j.1538-4632.1995.tb00338.x

Betarelli, J. A. A., \& Almeida, E. (2009). Os principais fatores internos e as exportações microrregionais brasileiras. Revista Economia Contemporânea, Rio de Janeiro, 13(2), 201-227. https://doi.org/10.1590/S1415-98482009000200002

Breitbach, A. C. M. (2008). Especialização e diversificação nas regiões industriais do Rio Grande do Sul. Porto Alegre: FEE (Texto para Discussão n. 31).

Cantú, J. J. S., \& Mollik, A. V. (2003). Efectos "Spillover" de las exportaciones en el crecimiento del producto manufacturero en las entidades federativas de México. Coloquio internacional "La mondialisation et ses effets: nouveaux débats nouvelles approaches". Retrieved from https://drjosesalazar.files.wordpress.com/2013/07/salazar-y-varella-2004.pdf

Carmo, A. S. S., Raiher, A. P., \& Stege, A. L. (2016). Spatial concentration of Brazilian exports of manufactured products: A microrregional analysis considering technological levels. Nova Economia, 26(3), 747-774. https://doi.org/10.1590/0103-6351/3374

Feder, G. (1982). On exports and economic growth. Journal of Development Economics, 12(1), 59-73.

Fotheringham, A. S., Brunsdon, C., \& Charlton, M. (2002). Geographically Weighted Regression: The Analysis of Spatially Varying Relationships. Hoboken, NJ: Wiley.

Galimberti, J. K., \& Caldart, W. L. (2010). As exportações e o crescimento econômico: Análise dos municípios do Corede Serra - 1997-04. Ensaios FEE, Porto Alegre, 31(1), 87-112.

Ibrahim, I. (2002). On exports and economic growth. Jurnal Pengurusan, 21, 3-18.

Lesage, J. P., \& Pace, R. K. (2009). Introduction to Spatial Econometrics. Boca Raton, FL: Chapman \& Hall/CRC. https://doi.org/10.1201/9781420064254

Mehdi, S., \& Shahryar, Z. (2012). The study examining the effect of export growth on economic growth in Iran. Business Intelligence Journal, 5(1), 21-27.

Miller, H. J. (2004). Tobler's first law and spatial analysis. Annals of the Association of American Geographers, 94(2), 284-289. https://doi.org/10.1111/j.1467-8306.2004.09402005.x

Perobelli, F. S., \& Haddad, E. A. (2006). Padrões de comércio interestadual no Brasil, 1985 e 1997. Revista Economia Contemporânea, 10(1), 61-88. https://doi.org/10.1590/S1415-98482006000100003

Seijo, C. S. (2000). La relación entre el crecimiento de las exportaciones y el crecimiento económico. Revista de ciências sociales (Río Piedras), (8), 170-194.

\section{Appendix A}

Table A1. Monte Carlo test for the stationarity of parameters

\begin{tabular}{cc}
\hline Variable & Statistics \\
\hline $\operatorname{CRESX}_{\mathrm{jt}}\left(1-\right.$ PARTX $\left._{\mathrm{jt}}\right)$ & $18,4^{*}$ \\
$\operatorname{CRESX}_{\mathrm{it}} * \operatorname{PARTX}_{\mathrm{jt}}$ & $2,73^{*}$ \\
$F T R A B_{j t}$ & 1,05 \\
$I N C F_{j t}$ & 1,20 \\
$\rho$ & 1,15 \\
Constant & 0,80 \\
\hline
\end{tabular}

Source: Estimated by the authors aided by the software GWR, based on the research data.

Note. * significant at $5 \%$ significance level.

\section{Appendix B}

\section{Description of the variables that integrate the empirical model}

\begin{tabular}{|c|c|}
\hline Variables & Description \\
\hline $\begin{array}{l}\operatorname{CRESX}_{\mathrm{i}}(1 \\
\left.-\operatorname{PARTX}_{\mathrm{i}}\right)\end{array}$ & $\begin{array}{l}\text { Represents the externality of exports in the economy. It is made up of two parts: the first refers to the exports growth, } \\
\text { while the second is the percentage of the GDP that does not correspond to the exports (production destined to the } \\
\text { domestic market). By multiplying these two components, the economy dynamics is obtained, result induced by the } \\
\text { exports growth. It seems relevant to emphasize that the exports values were in dollar (site AliceWeb) and were } \\
\text { converted into real (exchange rate - efetiva real - Ipeadata). }\end{array}$ \\
\hline
\end{tabular}




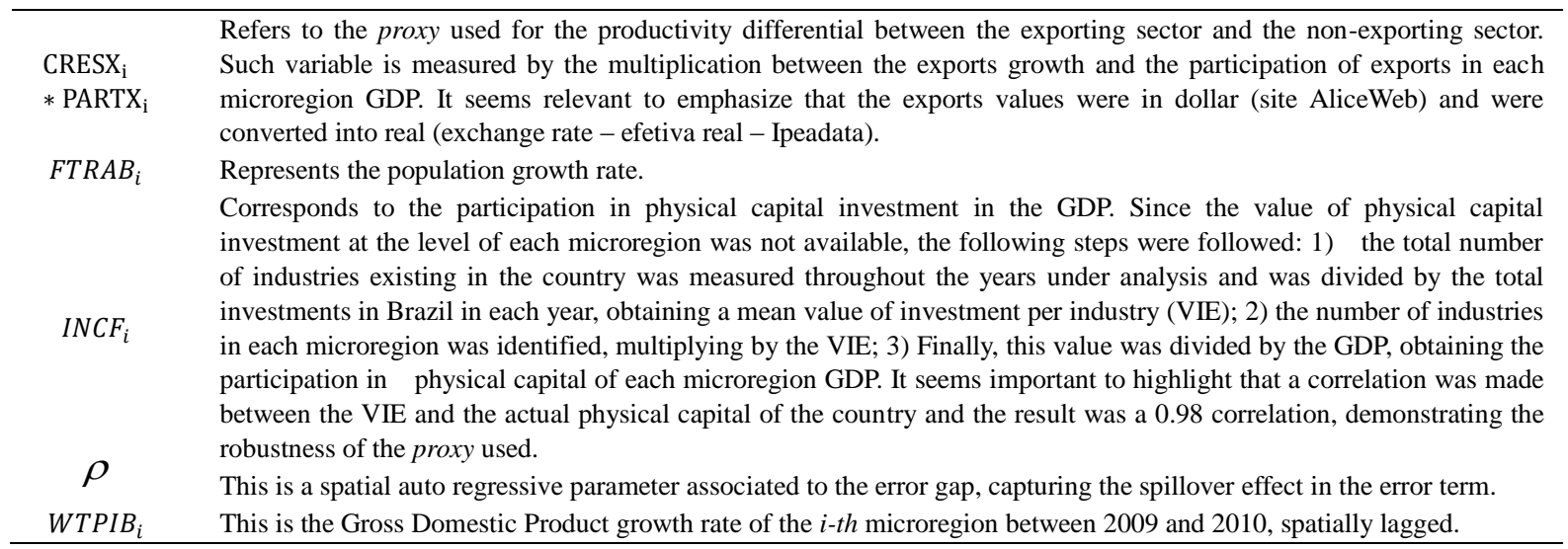

\section{Notes}

Note 1. The econometric model estimated in this study is specified in Equation 07, which is described in detail in the section addressing the methodology used.

Note 2. Also called LISA cluster map.

Note 3. The kernel spatial function is a real, continuous and symmetric function which uses the distance between two geographical points and a bandwidth parameter to determine the weight between these two regions, which is inversely related to the geographical distance.

Note 4. For a more detailed explanation of the types of kernel spatial function, see Fotheringham, Brundson and Charlton (2002).

Note 5. Bandwith is a softening parameter, so that the wider the band is, the more observations are used as calibrating point and the greater the local coefficient softening tends to be (Almeida, 2012).

Note 6. For a more detailed explanation of the models SEM, SDM and SLX see Lesage and Pace (2009).

Note 7. The models SEM, SDM and SLX were tested, however, the results of these models did not present statistical significance.

Note 8. The number of industries in each microregion was taken from the RAIS. Considering the total of industries in the country and dividing this number by the total investment, the distribution was carried out and used to calculate the physical capital of each region. It seems relevant to highlight that a correlation between this variable and the actual physical capital of the country was carried out and the result was a 0.98 correlation.

Note 9. It is important to emphasize the importance of the public policy in this process of the Brazilian external insertion, especially tax relief for exports. However, regarding agriculture, experts indicate that the productivity gains that the sector presented were the main factor for the greater international insertion that took place in 2000 (as can be observed in Figure 1).

Note 10. Equal 0.30.

Note 11. The ANOVA test was carried out for the GWR, and its value was 3.51. This test led to the conclusion that the GWR model represented some improvement in relation to the classical linear regression model which generated global coefficients. It seems relevant to highlight that the ANOVA test holds the null hypothesis that the GWR model does not improve the global model results.

\section{Copyrights}

Copyright for this article is retained by the author(s), with first publication rights granted to the journal.

This is an open-access article distributed under the terms and conditions of the Creative Commons Attribution license (http://creativecommons.org/licenses/by/4.0/). 